\title{
Does considering key audit matters affect auditor judgment performance?
}

\begin{abstract}
We investigate the impact of considering key audit matters (KAM) on auditor judgment performance and conducted a $2 \times 2$ between-subjects experiment based on a goodwill impairment testing case with 73 experienced auditors. We manipulated the two independent variables KAM consideration (present vs. absent) and client pressure (high vs. low). As dependent variables, we captured skeptical judgment and action as different facets of auditor judgment performance. Our results suggest that auditors' reaction to our client pressure manipulation is rather weak. If at all, auditors seem to become slightly more skeptical in their judgments and actions when client pressure is high, which might suggest that a reasonableness constraint has been triggered. Furthermore, we find that auditors exhibit significantly less skeptical judgment when KAM consideration is present than when KAM consideration is absent. This suggests that, when considering KAM, auditors are more willing to acquiesce to their clients' desired accounting treatments due to moral licensing.
\end{abstract}

JEL Classification: M42

Keywords: key audit matters, auditor judgment performance, motivated reasoning and goal commitment, moral licensing 


\section{Introduction}

The disclosure of key audit matters (KAM), i.e., "matters that, in the auditor's professional judgment, were of most significance in the audit [...]" (IAASB 2015a, paragraph 8), can be seen as one of the most prominent changes of the auditor's report since decades. For the first time, the auditor's report refrains from boilerplate wording, but rather provides insights into the auditor's work and, thus, detailed client-specific information are now publicly available for users. This concept is reflected by the new IAASB International Standard on Auditing ISA 701 'Communicating Key Audit Matters in the Independent Auditor's Report', which was published in January 2015 and is effective for audits of financial statements for periods ending on or after December 15, 2016.

There is some early evidence regarding the effect of a KAM section within the three following domains: Auditor liability (Backof, Bowlin, and Goodson 2014; Brasel, Doxey, Grenier, and Reffett 2016; Brown, Majors, and Peecher 2015; Gimbar, Hansen, and Ozlanski 2016a; Kachelmeier, Schmidt, and Valentine 2015), aggregated capital market reactions (Lennox, Schmidt, and Thompson 2016), and individual investors' decisions or assessments (Christensen, Glover, and Wolfe 2014; ${ }^{1}$ Köhler, Ratzinger-Sakel, and Theis 2016). The preliminary behavioral evidence concerning the studies on auditor liability suggest that KAM sections regarding subsequent litigation either reduce or do not influence auditor liability. However, a KAM section that specifically relates to the litigation issue may increase liability for two conditions. One, when the accounting standards are precise. Two, when the auditor discloses additional procedures performed to address the higher risk associated with the KAM (Gimbar, Hansen, and Ozlanski 2016b). With respect to aggregated market reactions, the

\footnotetext{
${ }^{1}$ The majority of these evidence is generated based on critical audit matters (CAM). CAM reflect the PCAOB's implementation of enhancing the auditor's reporting model in terms of communicating auditor insights to investors about critical audit issues. However, CAM are considered to be conceptually equivalent to KAM. Consequently, for the sake of consistency, we use the term KAM even if the original text refers to CAM.
} 
empirical evidence shows that investors do not find the expanded information in the auditor's report incrementally informative (Lennox et al. 2016). However, for individual investors' decisions, Christensen et al.'s (2014) experiment documents that investors who receive a KAM section are more likely to change their investment decision than are investors who receive a standard (i.e., old) audit report or investors who receive the same KAM section information in a management's footnote. However, the effect of a KAM section is reduced when offering a resolution paragraph.

Not only seemingly rather unattended by the IAASB ${ }^{2}$ but also lacking research evidence, ${ }^{3}$ is the possibility that requiring auditors to determine and report on KAM has side effects. The possibility of the occurrence of unintended consequences of a KAM section is acknowledged by the PCAOB based on practical deliberations (see PCAOB 2016 for further details). More specifically, the communication of KAM could potentially lead to changes in auditor behavior with either positive or negative effects on auditor judgment performance and/or audit quality. In addition, theoretical concepts rooted in psychology and prior audit research suggest that the necessity to consider KAM on a specific audit area might impact auditor judgment performance. In particular, in the context of auditing goodwill impairment testing, it seems possible that considering KAM either improves or impairs judgment performance, e.g. through goal commitment or a moral licensing effect. Consequently, the aim of this study is to assess the potential impact of considering KAM on auditor judgment performance. To address the aim of our study, reflecting the practical and theoretical dichotomy regarding the potential effect of KAM on auditor judgment performance, we use a competing

\footnotetext{
${ }^{2}$ To our knowledge, only the "Basis for Conclusions: Reporting on Audited Financial Statements - New and Revised Auditor Reporting Standards and Related Conforming Amendments" acknowledges the possibility that an additional focus on KAM "to be reported could indirectly result in an increase in professional skepticism and additional attention by the auditor on significant audit risks" (IAASB 2015b, 8).

${ }^{3} \mathrm{We}$ are only aware of one unpublished working paper that examines whether reporting an accounting estimate as a KAM can influence auditor judgment (Asbahr and Ruhnke 2017).
} 
hypotheses approach based on implications of motivated reasoning and goal commitment vs. moral licensing theory.

In addition, we include client pressure in investigating the impact of considering KAM on auditor judgment performance. This is of high relevance, because client pressure has been identified to pose a considerable threat to auditor judgment performance by previous literature. Dependent on the direction of the direct effect KAM consideration has on auditor judgment performance (improvement vs. impairment), KAM consideration might either represent an instrument to effectively debias auditor judgment performance under high client pressure, or amplify the effect high client pressure has on auditor judgment performance.

We carry out our study using a $2 \times 2$ between-subjects experiment based on a goodwill impairment testing case for the fictitious German electronics manufacturer Alpha. In our experiment with 73 experienced auditors from two Big4 audit firms in Germany, ${ }^{4}$ we manipulated the two independent variables KAM consideration (present vs. absent) and client pressure (high vs. low). With regard to the former independent variable, in the condition in which KAM consideration is present, participants were required to assess the likelihood that they will communicate matters regarding the estimation of the recoverable amount ${ }^{5}$ in a separate KAM section of the independent auditor's report. We opposed this condition with a condition where KAM consideration is absent, hence, where participants were required to assess the likelihood that they will communicate matters regarding the estimation of the recoverable amount only with those charged with governance. In line with Hatfield, Jackson, and Vandervelde (2011), the manipulation of the latter independent variable (client pressure)

\footnotetext{
${ }^{4}$ For more details, see section 3.

${ }^{5}$ As we conduct the experiment in an European normative environment, the case refers to IFRS in general and IAS 36 (IASB 2016) in particular. This is reflected by the terms used in this paper with regard to goodwill impairment. See also further descriptions in the section "Task".
} 
contains two different components: client importance and client opposition to making audit adjustments.

As dependent variables, we capture two facets of auditor judgment performance. First, we asked participants to assess the reasonableness of Alpha's estimation of the recoverable amount for the "Europe without Germany" cash generating unit ("skeptical judgment"). Second, we asked participants to indicate the likelihood that they will require Alpha to adjust the estimation of the recoverable amount ("skeptical action"). In this regard, it is important to underline that our experimental design allows us to draw a (careful) conclusion with regard to whether our manipulations improve or impair auditor judgment performance. As we seeded several issues that suggest that the recoverable amount is overstated, more conservative assessments and hence, more skeptical judgments and actions, tend to be more appropriate and represent better auditor judgment performance (see also Griffith, Hammersley, Kadous, and Young 2015 for a comparable approach).

Our results with regard to the independent variable client pressure suggest that auditors' reaction to our client pressure manipulation is rather weak and insignificant (based on ANOVAs). In an overall picture, if at all, auditors seem to become slightly more skeptical in their judgments and actions when client pressure is high. This direction of the effect would be contrary to our Hypothesis 1 which we derive from moral reasoning theory and might suggest that a reasonableness constraint has been triggered. Tests of mechanisms, based on the estimation of a structural equation model (SEM), further support this conclusion.

With regard to the independent variable KAM consideration, we find that auditors exhibit significantly less skeptical judgment when KAM consideration is present than when KAM consideration is absent. This suggests that, when considering KAM and due to moral licensing, auditors are more willing to acquiesce to their client's desired accounting treatments (Hypothesis 2b). While the moral licensing effect seems to be dominant, based on the SEM, we 
can provide empirical evidence that KAM consideration also induces a reverse effect on auditors' willingness to acquiesce to the client's preferred accounting through goal commitment (Hypothesis 2a).

To the best of our knowledge, this is the first study that examines the potential impact of considering KAM on auditor judgment performance. By showing that KAM consideration leads to less skeptical judgment, we document that the new KAM reporting requirement intended to improve the communicative value of the auditor's report for users (IAASB 2012) comes at the expense of auditor judgment performance. It seems as if auditors who consider KAM feel morally licensed to acquiesce to clients' desired accounting treatments. This finding is of interest for auditors and regulators, as well as users and prepares, by highlighting unintended consequences of KAM reporting.

The remainder of this study is structured as follows. In section 2, we develop the paper's hypotheses. Section 3 describes the experimental design as well as the participants. Section 4 reports the results as well as tests of mechanisms and additional analyses, and section 5 concludes.

\section{Hypotheses Development}

\section{Motivated Reasoning and Goal Commitment}

The motivated reasoning literature has found that individuals' decision processes are influenced by their goals and that "individuals committed to directional goals, or goals to reach a preferred conclusion, are more likely to reach their desired conclusion" (Kadous, Kennedy, and Peecher 2003, 762; see also Kunda 1990, 1999). Consistent with motivated reasoning, previous studies find that auditors tend to exploit ambiguity inherent in accounting standards to justify clientpreferred accounting (Hatfield et al. 2011; see also Ng and Tan 2003; Lord and DeZoort 2001; Salterio and Koonce 1997), when they have this respective directional goal (Hackenbrack and 
Nelson 1996; Kadous et al. 2003). Kadous et al. (2003) furthermore argue that auditor acceptance of client-preferred accounting increases with goal commitment, i.e. auditors' tendency of having directional goals to support client management's accounting choices and engaging in directional processing, and find that performing a quality assessment (as required by, e.g., SAS No. 90, see AICPA 2000) amplifies this effect. Consequently, with regard to our experiment, goal commitment would have a positive effect on auditors' assessment of the likelihood that the recoverable amount is reasonable (hence, leads to less skeptical judgment) and a negative impact on the assessment of the likelihood to require an adjustment of the recoverable amount (hence, leads to less skeptical action).

When client management exerts pressure on auditors, "audit partners and senior managers [...] may have a bias towards accepting management's perspective" (PCAOB 2011, 7). In how far client pressure might in fact impair auditor judgment performance, depends on several factors. Koch and Salterio (2015) argue that auditors who face very salient pressure to accept the client's aggressive accounting, likely “default to ingrained professional responses to deal with such challenges" (Koch and Salterio 2015, 11; see also Bauer 2015; Teoh 1992). Respective professional responses include, inter alia, developing an independent view or challenging management's conclusions (PCAOB 2011, 7). The application of ingrained professional responses is especially probable under circumstances where client pressure triggers the so-called reasonableness constraint (Boiney, Kennedy, and Nye 1997). The "reasonableness" criteria relates to the idea that auditors (or individuals in general) do not boundlessly follow directional goals, but rather as long as they can construct a case for themselves that makes them believe that an impartial third party would perceive the auditor as acting in a professional manner when evaluating client accounting. The "constraint" may be 
triggered if auditors feel challenged in their professional self-image, i.e. if they perceive a very high level of client pressure (Koch and Salterio 2017; see also Kadous et al. 2003). ${ }^{6}$

However, if client pressure is more subtle, auditors might have a greater focus on their commercial self-interest to maintain a solid and long-lasting relationship with the client. This in turn might lead auditors towards interpreting contextual facts so that the accounting preferred by the client seems acceptable (Koch and Salterio 2015; see also Hackenbrack and Nelson 1996), i.e. motivated reasoning. While client management may exert economic pressure upon the auditor by threatening to reduce audit/non-audit fees or to switch the auditor (Windsor and Kavanagh 2012), client management's (perceived) bargaining power will depend on the (economic) relevance the client has for the (engagement) auditor (or audit firm).

Based on the foregoing theoretical deliberations and in line with prior studies we predict that client pressure increases goal commitment and, consequently, auditor acceptance of clientpreferred accounting. With regard to our dependent variables and drawing from the general effect of goal commitment, we formally state the following hypothesis:

HYPOTHESIS 1. Auditors will exhibit less skeptical judgment and skeptical action when client pressure is high than when client pressure is low.

While goal commitment has been found to be increased by client pressure (e.g. Kadous et al. 2003), the effect of KAM consideration on auditors' directional goal to justify clientpreferred accounting has not been investigated thus far. In the context of auditing an accounting situation where authoritative guidance does not exist, Salterio and Koonce (1997) find that, when a client's position on an accounting matter is known to the auditor, and available precedents point to the same treatment of the accounting issue, auditors do not follow the client's position. However, when the available precedents are mixed with regard to their

\footnotetext{
${ }^{6}$ Koch and Salterio (2017) furthermore argue that the effect high or explicit client pressure has on auditor judgment is an on-average effect which is contingent on an auditor's perception of client pressure salience.
} 
implications for treating the accounting issue, "auditors tend to follow the client's position" (Salterio and Koonce 1997, 573). Trompeter (1994) argues that highly specific accounting standards limit auditors' range of acceptable options. Conversely, ambiguity in accounting standards might increase auditors' willingness to follow the client's position. In the same vain, however from a perception point of view, Gimbar et al. (2016a) find that jurors perceive precise accounting standards to constrain auditors' control over financial reporting outcomes, which in turn leads to a lower propensity for negligence verdicts when the accounting treatment conforms to the precise standard. However, the authors can show that either imprecise standards or KAM reduce the extent to which jurors perceive this constraint to exist, resulting in increased auditor liability. Hackenbrack and Nelson (1996) outline that auditors respond to moderate engagement risk by permitting the aggressive reporting method preferred by the client and justified their choice with aggressive interpretation of the applicable accounting standard. Yet, when confronted with high engagement risk, the auditors respond "by requiring conservative reporting and justified their choice with conservative interpretations of accounting standards." To summarize, while auditors seem to exhibit a tendency to accept client-preferred accounting in situations where there is leeway, the outlined findings also suggest that auditors might default to ingrained professional responses if circumstances so require. Since reporting issues within (a) KAM section(s) impose the pressure to justify the auditor's causal interpretations of the matter at hand to the addressees of the independent auditor's report outside the immediate sphere of the client, it seems reasonable to assume that the consideration of KAM decreases auditor acceptance of client-preferred accounting through reduced goal commitment. In other words, based on the implications of goal commitment, we would argue that auditors will exhibit more skeptical judgment and skeptical action when they consider KAM. However, in the following, we want to discuss another, yet related theoretical construct that seems relevant in 
the context of KAM consideration and would have different implications for the impact on auditor judgment performance.

\section{Moral Licensing}

Literature on moral licensing argues that disclosure might exacerbate biases, "because information providers are more comfortable providing biases when information recipients have been forewarned about the estimates' potential inaccuracy" (Griffin 2014, 1173; see also Cain, Loewenstein, and Moore 2011; Boiney et al. 1997). This effect has in particular been shown in contexts that involve conflicts of interest (Jamal 2012). Previous studies have shown that when people act in a way that increases their sense of their own ethicality, they feel "licensed" to act in a self-serving or even unethical manner (Jamal 2012; see for example Monin and Miller 2001, Miller and Effron 2010, Wilcox, Vallen, Block, and Fitzsimons 2009). For example, in an accounting context, Jamal, Marshall, and Tan (2016) find that disclosure of a conflict of interest increases bias in accountants' valuation estimates in favor of the client.

According to Jamal (2012), auditors might be particularly prone to moral licensing, as they face the conflict of interest of being charged with serving the public interest and being paid by their client at the same time. This reasoning clearly overlaps with the implications of motivated reasoning (Jamal 2012). Griffin (2014) argues that, in an auditing setting, "moral licensing could mean that auditors will be more willing to acquiesce to their clients' desired accounting treatments, believing either that the disclosure provides a suitable defense for not requiring adjustments $[\ldots]$, or that disclosure fulfills the auditors' fiduciary duty to ensure that the investing public has been informed" (Griffin 2014, 1173).

Clearly, the disclosure of KAM usually does not represent the disclosure of a conflict of interest for the auditor as used in prior moral licensing studies. More specifically, the auditor would for example not utilize KAM communication to disclose the conflict of interest of being charged with serving the public interest and being paid by the client. However, KAM 
communication might very well function in accordance with the implications of moral licensing, when a KAM is understood to be a disclaimer with regard to the matters described. In fact, preliminary behavioral evidence on the effect of KAM on auditor liability from the perspective of users of the independent auditor's report suggest that KAM sections regarding subsequent litigation either reduce or do not influence (perceived) auditor liability (Gimbar et al. 2016a).

Recapitulating the different theoretical implications and reflecting the theoretical dichotomy regarding the effect KAM consideration potentially has on auditor judgment performance, we chose to formally state two competing hypotheses. On the one hand, based on the implications of motivated reasoning and goal commitment, it seems reasonable to assume that auditors will exhibit more skeptical judgment and action when they consider KAM. Hence, we state the following hypothesis:

HYPOTHESIS 2a. Auditors will exhibit more skeptical judgment and skeptical action when KAM consideration is present than when KAM consideration is absent.

On the other hand, drawing from the implications of moral licensing, the opposite seems to be theoretically true as well. Consequently, the competing hypothesis reads as follows:

HYPOTHESIS 2b. Auditors will exhibit less skeptical judgment and skeptical action when KAM consideration is present than when KAM consideration is absent.

Including client pressure in the investigation of the effect of KAM consideration on auditor judgment performance is highly relevant. As outlined above, client pressure has been identified to pose a considerable threat to auditor judgment performance by previous literature. If KAM consideration reduces goal commitment and thus decreases auditor acceptance of client-preferred accounting (Hypothesis 2a), KAM consideration might in fact represent an instrument to effectively debias auditor judgment performance under high client pressure. If, 
however, auditors are more willing to acquiesce to their client's preferred accounting treatments when considering KAM due to a moral licensing effect (Hypothesis 2b), KAM consideration likely amplifies the effect high client pressure has on auditor judgment performance. Hence, dependent on the direction of the direct effect KAM consideration has on auditor judgment performance, the shape of an interaction effect between KAM consideration and client pressure differs. Combining the implications of Hypothesis 1/Hypothesis 2a vs. Hypothesis 1/Hypothesis $2 b$, we formally state the following - again competing - hypotheses for the interaction effect:

HYPOTHESIS 3a. When KAM consideration is present, the effect high client pressure has on skeptical judgment and skeptical action is mitigated.

HYPOTHESIS 3b. When KAM consideration is present, the effect high client pressure has on skeptical judgment and skeptical action is amplified.

\section{Potential Mediators}

We also investigate the mechanisms through which KAM consideration (present vs. absent) and client pressure (high vs. low) affect our dependent variables (skeptical judgment and skeptical action). First, we are interested in goal commitment as a potential mediator. To measure goal commitment, we draw on the scale used by Kadous et al. (2003), which requires participants to provide agreement ratings on different goals. The scale had been refined and validated by Klein, Wesson, Hollenbeck, Wright, and DeShon (2001) and is based on a more comprehensive scale developed by Hollenbeck, Williams, and Klein (1989). Due to time constraints and in line with previous literature, we only confront participants with the one directional goal relevant from a motivated reasoning perspective in an auditing context: to justify client-preferred accounting. More specifically, we provide the goal to "build a justifiable case for characterizing Alpha's estimation of the recoverable amount to be acceptable in the 
circumstances" and capture participants' agreement ratings on the five items shown in Table 1 (see also Kerler and Brandon 2010). ${ }^{7}$

[Insert Table 1 here]

Second, we also include work effort as a potential mediator in our analysis. To control for differences in effort exerted by participants is very important because of two reasons. One, effort has been found to positively affect auditor judgment performance (Libby and Luft 1993; Libby and Lipe 1992; Cloyd 1997) and hence, differences in effort exerted might explain results. Two, systematic differences in effort exerted related to the independent variable KAM consideration might help to shed light on the mechanisms through which KAM consideration affects our dependent variables. In particular, we argue that if the KAM consideration present condition was associated with less work effort, this would be indicative of a moral licensing effect: auditors feel licensed to exert less effort and have less motivation to conduct a thorough audit. We measure work effort by asking participants for a self-assessment of how hard they worked on the provided case (on a 11-points Likert scale with endpoints labeled as "not at all hard" and "extremely hard"). Figure 1 shows the outline of the structural equation model (SEM) that we estimated in order to investigate the mechanisms through which client pressure and KAM consideration affect our dependent variables.

[Insert Figure 1 here]

\footnotetext{
${ }^{7}$ With regard to the five items, high ratings on items $\mathrm{x}_{1}$ and $\mathrm{x}_{2}$ and low ratings on items $\mathrm{x}_{3}-\mathrm{x}_{5}$ correspond with high goal commitment.
} 


\section{Method}

\section{Experimental Design and Participants}

We used a paper-and-pencil based $2 \times 2$ between-subjects experimental design ${ }^{8}$ and manipulated the two independent variables KAM consideration (present vs. absent) and client pressure (high vs. low). ${ }^{9}$ We conducted the experiment with 73 experienced auditors of two German Big4 audit firms. ${ }^{10}$ The 73 auditors in our sample possess an average work experience in the audit profession of 5.97 years $(\mathrm{SD}=5.09$; median $=5)$, with 26 of the participants being certified auditors. 21.43 percent/18.57 percent of the participants are consultants/senior consultants, 40.00 percent/4.29 percent of the participants are managers/senior managers, and 15.71 percent of the participants are directors or partners. 32.82 percent of the participants are female.

\section{Task}

We provided participants with a comprehensive auditing case study. ${ }^{11}$ The case study contained information on the fictitious German electronics manufacturer Alpha. Participants learned that Alpha is a German publicly traded corporation ("Aktiengesellschaft") listed in the German

\footnotetext{
${ }^{8}$ To ensure that participants could not revise previously given answers when working on subsequent parts of the experimental materials, we split up the materials to four envelopes which had to be opened and sealed in a specific sequence.

${ }^{9}$ The design of the experiment meets the requirements for using human subjects in the experimental laboratory at the university where one of the authors is located. The use of human subjects was also approved by the audit firms. ${ }^{10}$ Each of the two Big4 audit firms reserved slots for the experiment on staff training days. The three sessions took place within several weeks around the turn of the year of 2016/17. Since ISA 701 is effective for audits of financial statements for periods ending on or after December 15, 2016, at that time, (senior) auditors should have had knowledge of, but limited experience with KAM. In fact, 80.85 percent of our participants indicated that they had heard about KAM before they participated in our experiment. Our initial sample comprises 182 persons. Herein included are 25 IT staff who participated in one of the training days together with experienced auditors. Since we could not exclude them from participating in the experiment ex ante, we deleted their responses from the sample ex post. Furthermore, we excluded 52 participants who failed our manipulation check in the post experimental questionnaire related to the independent variable KAM consideration. Of the remaining participants, we do not consider 32 participants who had not more than 6 months of or did not indicate their work experience in auditing (of those 32 participants, 15 did not provide their work experience in years).

${ }^{11}$ We based our experimental material on the Trueblood Gator Electronics case study which is available online for teaching and academic research (see Deloitte 2016). Since we conducted the experiment in an European normative environment, we had to significantly adapt the original (US-GAAP and US Auditing Standards based) case study. Our case study was carefully reviewed and improved by two senior auditors of two Big4 audit firms before we conducted the experiment.
} 
Prime Standard and that Alpha publishes group financial statements (in line with IFRS). ${ }^{12}$ The case study furthermore contained specific information on Alpha's goodwill impairment analysis for the "Europe without Germany" cash generating unit in line with IAS 36, including valuation schedules and detailed information on management's assumptions underlying the estimation of the value in use.

According to IAS 36, an asset is impaired when its carrying amount exceeds its recoverable amount (IASB 2016, paragraph 8). The standard thereby defines the recoverable amount as the higher of an asset's or cash-generating unit's fair value less costs of disposal and its value in use (IASB 2016, paragraph 18). Participants are informed that, on the basis of its own valuation, Alpha has estimated that the recoverable amount of all cash generating units exceeded their respective carrying amount. Hence, a goodwill impairment did not occur.

The participants were instructed to assume that they are the engagement partner and in charge of the current audit of Alpha's group financial statements for the financial year ending on December 31, 2015, ${ }^{13}$ and that they are planning to audit the current-year goodwill impairment analysis of the "Europe without Germany" cash generating unit. Thereby, participants learned that their audit firm has also audited Alpha's group financial statements for the past two years. ${ }^{14}$ Participant are informed that they had determined earlier that goodwill for

\footnotetext{
${ }^{12}$ ISA 701 would require Alpha's group auditor to report on KAM for audits of financial statements for periods ending on or after December 15, 2016 (see IAASB 2015a).

${ }^{13}$ While Alpha generally qualifies as a group for which the group auditor would have to report on KAM in line with ISA 701, reporting is only mandatory for audits of financial statements ending on or after December 15, 2016. However, voluntary earlier application of ISA 701 is possible (IAASB 2015b, paragraph 7). This is important for our manipulation of the independent variable KAM consideration, as both the condition in which KAM consideration is present, as well as the condition in which KAM consideration is absent, is plausible for an audit of financial statements ending on December 31, 2015.

${ }^{14} \mathrm{We}$ chose the outlined auditor tenure with purpose: providing no information on tenure, or setting tenure either very short (i.e., one year) or very long (i.e., many years) seems to bear the risk of inducing unintended biases (see comprehensive literature on auditor tenure, e.g., Knechel and Vanstraelen 2007, Ghosh and Moon 2005, Carcello and Nagy 2004, Geiger and Raghunandan 2002). Instead, we set auditor tenure to be moderate and chose three years because Alpha's estimation of the value in use is based on free cash flows derived from audited financial statements for the financial years ending on December 31, 2013 and 2014, and the (unaudited) current financial statements for the financial year ending on December 31,2015. Hence, participants should not worry much about the reliability of historical figures in Alpha's estimation, since their own audit firm has performed the audit.
} 
the "Europe without Germany" cash generating unit is a material account balance as of December 31, 2015, because it is quantitatively significant (280 million EUR) and qualitatively significant because its susceptibility to misstatement arising primarily from recent market declines.

Participants could understand from the provided materials that the carrying amount of the "Europe without Germany" cash generating unit amounts to 730,000 TEUR, that the fair value less costs of disposal amounts to 700,000 TEUR, and that the value in use amounts to 1,040,292 TEUR. ${ }^{15} \mathrm{We}$ informed participants that Alpha's estimation of the fair value less costs of disposal is based on a competitor's recent purchase offer and that their team has already evaluated the appropriateness of the estimation. Our intention was that participants do not further worry about the fair value less costs of disposal, but rather focus on Alpha's estimation of the recoverable amount. In this regard, we tell participants that their team has only evaluated the mathematical accuracy of the model and that, consequently, their job will be to evaluate Alpha's assumptions underlying the estimation of the value in use of the "Europe without Germany" cash generating unit and to form a preliminary conclusion about its reasonableness.

To determine the value in use, Alpha has used a discounted cash flow method (free cash flow approach). Alpha's projections of future revenue, operating expenses, capital expenditures, and the estimated weighted average cost of capital (WACC) are important drivers of the cash generating unit's equity value (= value in use) (Griffith et al. 2015). For the purpose of our study it was important that Alpha's goodwill impairment analysis of the "Europe without Germany" cash generating unit bears the potential to qualify as a matter to be communicated as KAM. Hence, we seeded several issues that suggest that the recoverable amount is overstated. The model indicates a significant increase in revenue, EBITDA, and cash flows over

\footnotetext{
${ }^{15}$ Since the fair value less costs of disposal falls below the value in use, it is the value in use that leads to the conclusion that an impairment of the cash generating unit is not necessary.
} 
the projected period (see for all issues also Deloitte 2016). In particular, (1) there is a large growth in total revenue of 11.21 percent in 2017 , and (2) the growth rate in the last projected period 2020 (5.07 percent) lies substantially above the expected long-term growth rate of 3.0 percent. Furthermore, (3) projected capital expenditures do not track the expected growth in revenue over the projected period, which would ordinarily be the case. Finally, (4) the working capital assumption for the projected periods is 0 percent, and working capital as a percentage of incremental revenue appears to be low based on current levels of working capital and revenue. ${ }^{16}$ Each of the four issues ceteris paribus increases the estimated amount of the equity value of the cash generating unit. We emphasize that our seeded issues were not supposed to qualify as formal errors, but rather to make Alpha's hockey stick projections salient. While the goodwill impairment analysis should bear the potential to qualify as a matter to be communicated as KAM, it was necessary to avoid that participants think of it in terms of a modified or adverse opinion.

It is important to underline that our experimental design allows us to draw a (careful) conclusion with regard to whether our manipulations improve or impair auditor judgment performance. As we seeded several issues that suggest that the recoverable amount is overstated, more conservative assessments and hence, more skeptical judgments and skeptical actions, tend to be more appropriate and represent better auditor judgment performance (see also Griffith et al. 2015 for a comparable approach).

\section{Independent Variables}

We look at the impact of the two independent variables KAM consideration and client pressure on auditor judgment performance. The following manipulations are implemented in the

\footnotetext{
${ }^{16}$ As already outlined before, our case study was carefully reviewed and improved by two senior auditors of two Big4 audit firms before we conducted the experiment. In particular, the senior auditors confirmed that the seeded issues should be potentially identifiable by our participants. However, they argued that the salience of issues (1) and (2) is greater than the salience of issues (3) and (4). Furthermore, the senior auditors confirmed that our (final) case study is very realistic.
} 
introductory part of the case study, where participants receive rather general information on Alpha and their own role. Most importantly, participants receive the treatment before they work on the task.

The independent variable KAM consideration is manipulated as follows. While it can be assumed that senior auditors have either received training on, or are at least informed about KAM, more junior auditors may not have the same knowledge. As a consequence, levels of knowledge might differ between participants. ${ }^{17}$ Hence, we chose to include a reminder on KAM requirements in the KAM consideration present condition. There, we first of all provide participants with the following very basic information on KAM:

"Furthermore, assume that you are required to communicate key audit matters (KAM) in a separate section of the independent auditor's report under the heading "Key Audit Matters" in line with ISA 701. KAM are those matters that, in the auditor's professional judgment, were of most significance in the audit of the financial statements and are selected from matters communicated with those charged with governance, but are not intended to represent all matters that were discussed with them."18

Then, participants also learn: "At some point during your work on this case you will be asked to assess the likelihood that you will communicate matters regarding Alpha's estimation of the recoverable amount for the "Europe without Germany" cash generating unit in the separate Key Audit Matters section of the independent auditor's report."

Hence, in this condition, participants consider whether it is likely that the evaluation of Alpha's assumptions underlying the estimation of the value in use of the "Europe without

\footnotetext{
${ }^{17}$ For, example, it is likely that a (senior) auditor who is mostly auditing larger listed clients, has deeper insights into KAM than a (senior) auditor who is mainly working for smaller non-listed clients. In fact, we control for participants' prior knowledge on KAM (see also footnote 10).

${ }^{18}$ The wording of this passage is derived from ISA 701, see IAASB 2015a, paragraph 9.
} 
Germany" cash generating unit and forming a preliminary conclusion about its reasonableness is a KAM or not. As a post experimental question, we later indeed capture participants' assessment of the likelihood that they will communicate matters regarding Alpha's estimation of the recoverable amount for the "Europe without Germany" cash generating unit in the separate Key Audit Matters section of the independent auditor's report.

Designing the condition in which participants should not consider KAM (KAM consideration absent condition) is more challenging. Since KAM are not mandatory for financial statements for the financial year ending on December 31, 2015, an auditor working through our case study would not naturally consider KAM if the case study was silent on KAM. However, just being silent on KAM in the condition in which we do not want auditors to consider KAM, did not seem appropriate. We rather chose to draw the participants' attention to the extant communication requirements of ISA 260 and assume that the participants will neglect any potential consideration of KAM. Instead, we therefore instruct participants as follows:

"Furthermore, assume that you are required to provide those charged with governance with timely observations arising from the audit that are significant and relevant to their responsibility to oversee the financial reporting process in line with ISA 260. Matters to be communicated include, e.g., the auditor's views about significant qualitative aspects of the entity's accounting practices, significant difficulties, if any, encountered during the audit, and other matters, if any, arising from the audit that, in the auditor's professional judgment, are significant to the oversight of the financial reporting process." $" 19$

\footnotetext{
${ }^{19}$ The wording of this passage is derived from ISA 260, see IAASB 2015c, paragraphs 16, 21.
} 
Then, participants also learn: "At some point during your work on this case you will be asked to assess the likelihood that you will communicate matters regarding Alpha's estimation of the recoverable amount for the "Europe without Germany" cash generating unit with those charged with governance."

Again, as a post experimental question, we later indeed capture participants' assessment of the likelihood that they will communicate matters regarding Alpha's estimation of the recoverable amount for the "Europe without Germany" cash generating unit with those charged with governance.

Hence, in the condition in which we do not want auditors to consider KAM, we confront them with the well-known standard requirement to communicate relevant matters with those charged with governance in line with ISA 260 "Communication with those charged with Governance" (IAASB 2015c). ${ }^{20}$ Because KAM are selected from the matters communicated with those charged with governance (IAASB 2015a, paragraph 8), in both conditions, the salience of and the perceived risk associated with the goodwill impairment issue at hand should be rather similar. ${ }^{21}$ Consequently, as intended, observed differences in auditor judgment performance should relate to an aspect that distinguishes KAM requirements from the requirement to communicate with those charged with governance: publicly communicating matters that, in the auditor's professional judgment, were of most significance in the audit, to external users of the independent auditor's report.

\footnotetext{
${ }^{20}$ Please note that ISA 260 was revised in connection with the introduction of KAM. The revision mainly relates to the fact that KAM are selected from the matters communicated with those charged with governance. While the revision of ISA 260 and the introduction of KAM should lead to more intense communication between the auditor and those charged with governance, the revision of ISA 260 does not affect our manipulation.

${ }^{21}$ Participants were asked to indicate the likelihood that they will communicate matters regarding Alpha's estimation of the recoverable amount for the "Europe without Germany" cash generating unit in the separate key audit matters section of the independent auditor's report/with those charged with governance on a 11-points Likert scale with endpoints labeled as "not at all likely" and "extremely likely". Mean responses for the KAM consideration present/absent conditions are 6.86 and 7.07, respectively, and do not differ significantly. This also suggest that auditors do not exhibit a general reluctance to report on KAM, which could have had implications for the interpretation of our results.
} 
Intentionally, we manipulated KAM consideration as opposed to the act of reporting KAM itself out of several reasons. First, telling participants that the matter at hand qualifies as a KAM that has to be reported should significantly impact their judgments and should preclude assessments representing low levels of skeptical judgment and skeptical action. Second, the definition of KAM suggests that the decision to report a matter at hand in the independent auditor's report as a KAM should rather be the outcome of performing the audit and the result of auditor's professional judgment (IAASB 2015a, paragraph 8,9 ), instead of providing the underlying assumption for the audit. Third, it seems reasonable to assume that KAM do not only affect auditor judgment in cases where KAM are de facto reported, but already when auditors just consider reporting KAM. That is because considering KAM involves taking the act of reporting into account, which should be sufficient to activate the respective cognitive processes in line with our theoretical argumentation.

We check for the salience of our KAM consideration manipulation with a manipulation check question in the post-experimental questionnaire. We simply ask participants to select what task was part of the case study from four provided options. Two of the options relate to realistic, but for our experiment irrelevant, audit tasks (issuance of a going-concern opinion, assessment of the work of the internal audit function), while one option relates to the communication of matters as KAM/with those charged with governance, respectively. We only included those participants in our final analysis that were able to correctly indicate the task they faced.

The independent variable client pressure is manipulated to be either high or low. In line with Hatfield et al. (2011), the manipulation contains the two different components, client importance and client opposition to making audit adjustments. When client pressure is manipulated to be low, the participants are informed that: 
"Alpha is one of several larger clients you are in charge of as an engagement partner. Consequently, only a limited amount of your time will be dedicated to serving this client in the current year. Last year's audit has shown, that, in general, Alpha's CFO is not opposed to making audit adjustments".

In comparison, when client pressure is manipulated to be high, the participants are informed that:

"Alpha is the only larger client you are in charge of as an engagement partner. Consequently, a significant amount of your time will be dedicated to serving this client in the current year. Last year's audit has shown, that, in general, Alpha's CFO is rather opposed to making audit adjustments.”

Similar to Hatfield et al. (2011), we are not interested in understanding which of the two components of client pressure (client importance and client opposition) drives the construct, as this would be of minor relevance for our study. Consequently, to keep the amount of required participants low, we also do not combine low/high client importance with high/low client opposition in our experiment (Hatfield et al. 2011).

In order to test for the effectiveness of our client pressure manipulation, we asked participants for their agreement ratings for the following three statements (on 5-points Likert scales with endpoints labeled as "agree completely" and "disagree completely"; see also Hatfield et al. 2011) in the post experimental questionnaire: (1) "Alpha is important to me as a client", (2) "If I required an accounting adjustment from Alpha's CFO, s/he would heavily complain", and (3) "While considering Alpha's estimation of the recoverable amount, I felt pressure to avoid requiring an accounting adjustment from Alpha's CFO”. We find a significant difference in the expected direction in the mean assessments between the two client pressure conditions (low vs. high) for the second question only (one-tailed t-test, $\mathrm{p}=0.069$ ). Hence, we 
can provide empirical evidence for a successful manipulation of the client pressure component client opposition. Since there are no significant differences between groups for the other client pressure related manipulation check questions, we have to acknowledge that our client pressure manipulation might be weaker than intended. While the utilized client pressure manipulation has been very successful in prior studies, because of the described findings, it might be fruitful for further research to develop an understanding for the conditions under which this client pressure manipulation works well.

\section{Dependent Variables}

We capture two facets of auditor judgment performance with our dependent variables. First, we asked participants to assess the reasonableness of Alpha's estimation of the recoverable amount for the "Europe without Germany" cash generating unit (Griffith at al. 2015). Answers were to be provided on an 11-points Likert-scale with endpoints labeled as "not at all likely/extremely likely to be reasonable". In terms of professional skepticism, this first dependent variable would relate to skeptical judgment (Nelson 2009). Second, we ask participants to indicate the likelihood that they will require Alpha to adjust the estimation of the recoverable amount (an 11-points Likert-scale with endpoints labeled as "not at all likely/extremely likely" was provided for responses). The second dependent variable would relate to skeptical action in terms of professional skepticism (Nelson 2009). It is important to capture these two distinct aspects of auditor judgment performance (Shaub and Lawrence 2002), because "skeptical judgments need to reach a threshold to create action, and incentives associated with budget, time pressure, peer and superior, or client can prevent action" (Nelson 2009, 16). To avoid the possibility that we observe consistent response patterns for our dependent variables (i.e., low values for skeptical judgment and skeptical action) just because participants inattentively select the same response option on the scale for both questions, we phrased the questions so that low/high 
values on the scale represent more skeptical judgment/action (see questions and endpoints above).

\section{Results}

\section{Tests of Hypotheses}

Figure 2 outlines the descriptive results for our dependent variables. ${ }^{22}$ Descriptive results suggest that auditors' reaction to our client pressure manipulation is rather weak. Although participants who consider KAM tend to assess the likelihood that the recoverable amount is reasonable to be marginally higher when client pressure is high, in an overall picture, if at all, auditors seem to become slightly more skeptical in their judgments and actions when client pressure is high. This direction of the effect would be contrary to our Hypothesis 1 and might suggest that a reasonableness constraint has been triggered. Auditors who perceive very salient client pressure might feel challenged in their self-image as independent professionals, making them become more skeptical in their judgments and actions (Koch and Salterio 2017; see also Kadous et al. 2003; Bauer 2015, Teoh 1992).

\section{[Insert Figure 2 here]}

However, in separate ANOVAs for both dependent variables, we do not find significant differences between groups related to the client pressure manipulation (see Table 2 for more details with regard to skeptical judgment). Consequently, we are neither able to accept Hypothesis 1 nor can we provide evidence for a significant contrary effect indicative of a reasonableness constraint. Our results could suggest that the relatively experienced auditors in our sample are quite immune to client pressure. However, we want to underline that the success

\footnotetext{
${ }^{22}$ Observations are distributed across cells as follows: 16, 20, 20, and 17 in the KAM present/client pressure low, KAM present/client pressure high, KAM absent/client pressure low, and KAM absent/client pressure high condition. Since experimental materials were randomly handed out to participants, we neither expected nor find systematic differences between groups with regard to individual characteristics (age, gender, experience, etc.).
} 
of our client pressure manipulation is uncertain. While the results for our manipulation check questions (see section "Independent Variables") might suggest that our client pressure manipulation is weaker than intended, a possibly triggered reasonableness constraint would instead lead to the conclusion that the pressure was too salient.

Descriptive results further suggest that auditors assess the likelihood that the recoverable amount is reasonable to be substantially higher when they consider KAM. Correspondingly, the data indicates that auditors assess the likelihood that they will require the client to adjust the estimation of the recoverable amount to be (slightly) lower when they consider KAM. A significant direct effect of KAM consideration $(p=0.0875)$ on the dependent variable skeptical judgment is confirmed by an ANOVA (see Table 2). However, we do not find significant differences between groups for the dependent variable skeptical action (ANOVAs regarding this variable are not tabulated). Consequently, as for skeptical judgment, we are able to support Hypothesis $2 \mathrm{~b}$ : Auditors exhibit significantly less skeptical judgment when KAM consideration is present than when KAM consideration is absent. This suggests that, when considering KAM and due to moral licensing, auditors are more willing to acquiesce to their clients' desired accounting treatments, believing either that KAM communication provides a defense for not requiring adjustments, or that KAM communication fulfills the auditors' fiduciary duty to ensure that the investing public has been informed. Hence, our findings suggest that when auditors consider KAM, auditor judgment performance is impaired. Finally, we do not find significant interaction effects between the two independent variables KAM consideration and client pressure and we can consequently neither support $\mathrm{H} 3 \mathrm{a}$ nor $\mathrm{H} 3 \mathrm{~b}$ (see Table 2; ANOVA results for the dependent variable skeptical action are not tabulated).

[Insert Table 2 here] 


\section{Tests of Mechanisms}

We also investigate the mechanisms through which KAM consideration and client pressure affect our dependent variables (skeptical judgment and skeptical action) and we are mainly interested in two factors as potential mediators: Goal commitment and work effort. Figure 3 shows the path coefficients and the respective significance levels ${ }^{23}$ for the SEM that we estimated $(n=70) .^{24}$

As can be seen from Figure 3 (and Table 3), the SEM reveals that our client pressure manipulation has a significant positive impact on the likelihood that the auditors require an adjustment of the recoverable amount $(\mathrm{p}=0.020$, coef. $=0.919)$, which is in line with the descriptive results outlined above. Hence, high client pressure is associated with more skeptical action, which is indicative of a reasonableness constraint being triggered for our participants. Koch and Salterio (2017) argue that the effect high or explicit client pressure has on auditor judgment is an on-average effect which is contingent on an auditor's perception of client pressure salience. In other words, the observable direction of the effect depends on whether the reasonableness constraint is triggered on average, or not. Taking furthermore into account that the observation of a reasonableness constraint implies salient client pressure, it does not seem very reasonable anymore to assume that our client pressure manipulation was too weak. Instead, we believe that our client pressure manipulation triggered the reasonableness constraint for a substantial proportion of our participants, but worked as intended for others, leading to the rather small on-average effect that we find.

[Insert Figure 3 and Table 3 here]

\footnotetext{
${ }^{23}$ The asterisks indicate significance levels as follows (two-tailed tests): $* * * 1$ percent significance level; $* * 5$ percent significance level; $* 10$ percent significance level. For the variables constituting the latent variable goal commitment, see also Table 1 . All reported p-values are based on a two-tailed test.

${ }^{24}$ We estimate standard linear SEM (maximum likelihood) using STATA software. Due to missing values for variables that are included in the SEM, the $\mathrm{n}$ is smaller than the $\mathrm{n}$ reported for the tests of hypotheses.
} 
Furthermore, consideration of KAM significantly increases participants' assessment of the likelihood that the recoverable amount is reasonable $(p=0.036$, coef. $=1.168)$, which is indicative of a moral licensing effect, and again supports Hypothesis 2b. The SEM now additionally sheds light on the mechanism being at work. First, consideration of KAM also significantly reduces the work effort exerted by participants $(p=0.014$, coef. $=-1.306)$, which is again indicative of a moral licensing effect as auditors seem to feel licensed to exert less effort and seem to have less motivation to conduct a thorough audit. In this regard, we can rule out that the effect is due to differences in group composition, as we test for, but do not find systematic differences between groups with regard to individual characteristics (age, gender, experience, etc.) of the participants.

However, we can also show that (1) consideration of KAM significantly reduces goal commitment $(p=0.087$, coef. $=-0.2047)$. Goal commitment in turn (2) has a positive (albeit non-significant) effect on participants' assessment of the likelihood that the recoverable amount is reasonable $(p=0.305$, coef. $=0.873)$, and a significantly negative effect on the likelihood that the auditor requires an adjustment of the estimation of the recoverable amount $(p=0.077$, coef. $=-1.358)$. Considering the effects (1) and (2) together, KAM consideration might have the potential to lead to more skeptical action through a decrease of goal commitment. The outlined mechanism reflects exactly what we had hypothesized in Hypothesis 2a. Hence, while the moral licensing effect seems to be dominant, we can provide empirical evidence that KAM consideration also induces a reverse effect on auditors' willingness to acquiesce to the client's preferred accounting through goal commitment. Looking at the total effect KAM consideration has on participants' assessment of the likelihood that the recoverable amount is reasonable further supports the notion of a reverse effect: the total effect is smaller than the direct effect reported above $(\mathrm{p}=0.037$, coef. $=1.081$; untabulated $)$. 
Finally, not surprisingly, the path coefficient between skeptical judgment and skeptical action is highly significant (and negative, which makes perfect sense if the response scales underlying the variables are considered, see section "Dependent Variables"; $p=0.000$, coef. $=$ -0.623). In line with the implications of previous studies, the work effort exerted by the auditor significantly improves judgment performance, as it has a significantly positive impact on the likelihood that the auditor requires an adjustment of the estimation of the recoverable amount $(p=0.008$, coef. $=0.232)$, and a (albeit non-significant) negative impact on the assessment of the likelihood that the recoverable amount is reasonable $(\mathrm{p}=0.541$, coef. $=-0.070)$.

With a total of 70 observations, we do not meet existing rules of thumb for the minimum sample size in structural equation modelling (e.g., 10 observations per indicator; Nunnally 1967; Kahai and Cooper 2003), or even stricter sample size requirements (see Westland 2010 for an overview). More generally, when sample sizes are under 100, nonconvergence and improper values might be a problem. However, sample sizes as small as $n=50$ can produce reliable results under certain conditions (Hoyle and Gottfredson 2015) in SEM, and previous studies have worked with sample sizes comparable to or smaller than our sample size (van Raaij and Schepers 2006; So and Bolloju 2005; Venkatesh and Davis 2000; Yoo and Alavi 2001). Especially when the estimation converges - as in our case - concerns shift to the evaluation of fit (Hoyle and Gottfredson 2015). The likelihood ratio chi-square test that compares our model to a saturated model that has no degree of freedom is insignificant $(p=0.3349)$, which suggests that our model might fit the data well. The overall equation-level goodness of fit $\mathrm{R}^{2}$ is 0.2705 . As we lose a significant amount of observations based on a manipulation check question (as outlined before), we included observations deleted for the described main analyses and reran the SEM for the additional analyses in the following section in order to mitigate a potential sample size concern. 


\section{Additional Analyses}

We conducted additional analyses to validate our results as well as the conclusions. Given the high complexity of our case, we repeated all described analyses with the most experienced auditors in our sample only. More specifically, if we only consider participants with a work experience in auditing above the median work experience in our sample (five years), the results and implications discussed for the tests of hypotheses generally do not change. Rather, the direct effect KAM consideration has on skeptical judgment becomes stronger and more significant ( $\mathrm{p}$ $=0.01, \mathrm{n}=42$ ). Unfortunately, the SEM does not converge for this partitioning of the sample because of the small $n$.

If we instead add those participants to our sample who possess not more than six month of work experience in auditing, response patterns in the tests of hypotheses as well as mechanisms remain largely consistent, but significances diminish. Given the fact that our case actually requires a certain level of skills and knowledge in auditing, it is not very surprising that including a considerable proportion of rookies and interns in the analyses induces too much noise.

As outlined before, we lose a number of observations by excluding those participants from further analyses who fail to indicate what task related to the KAM consideration manipulation was part of the case study. As participants tend to exert less effort in a postexperimental questionnaire, especially when the case itself was challenging, failure to state whether they had to consider KAM, or not, might rather be indicative of inattentiveness, than of the ineffectiveness of our manipulation. Consequently, we reran all analyses and include participants that failed the respective manipulation check question and have more than six month of work experience in auditing. Response patterns in the tests of hypotheses remain consistent $(n=107)$. In fact, the direct effect KAM consideration has on skeptical judgment becomes more significant $(\mathrm{p}=0.054)$. 
Including more observations in the analyses is in particular relevant with regard to the SEM that we estimate for the tests of mechanisms to increase power of the results. Repeating the analyses with the above described sample $(n=101)^{25}$ reveals that the signs of all relevant path coefficients correspond with those reported in Table 3. While we again find that consideration of KAM significantly increases participants' assessment of the likelihood that the recoverable amount is reasonable $(\mathrm{p}=0.018$, coef. $=1.050)$, and that work effort exerted by the auditor significantly improves judgment performance, as it has a significantly positive impact on the likelihood that the auditor requires an adjustment of the estimation of the recoverable amount $(\mathrm{p}=0.01$, coef. $=0.223)$, significances diminish for other path coefficients and fall short of a 10 percent significance level $(\mathrm{p}=0.133$ for the path coefficient between consideration of KAM and goal commitment; $p=0.142$ for the path coefficient between consideration of KAM and work effort; $\mathrm{p}=0.224$ for the path coefficient between goal commitment and skeptical action). When we run the SEM with all observations (and hence disregard work experience in auditing), in addition to significant findings similar to those just described, we can further provide evidence for the effect of goal commitment on skeptical judgment $(\mathrm{p}=$ 0.059 , coef. $=1.043)$ and skeptical action $(p=0.094$, coef. $=-0.914$; all results described in this section are untabulated).

With our comprehensive additional analyses we want to (1) underline that the main effects of KAM consideration described in this paper are robust to meaningful partitioning of the full sample, and (2) to make transparent that the tests of mechanisms tend to be sensitive to sample composition. However, while more restrictive sample composition in the main analyses generates significant results, a sample dilution (i.e., the inclusion of less experienced auditors/auditors that fail the manipulation check question) generally does not change the

\footnotetext{
${ }^{25}$ Due to missing values for variables that are included in the SEM this $\mathrm{n}$ is smaller than the $\mathrm{n}$ reported for the tests of hypotheses.
} 
observable pattern in mechanisms, but rather leads to diminishing significances for some path coefficients.

\section{Conclusion}

With our $2 \times 2$ between-subjects experiment with 73 experienced auditors from two Big 4 audit firms in Germany we addressed the question of how considering KAM affects auditor judgment performance. We manipulated the two independent variables KAM consideration (present vs. absent) and client pressure (high vs. low) and investigated how they impact our dependent variables, two different facets of auditor judgment performance (skeptical judgment and skeptical action).

Our main results are as follows: First, in the test of hypotheses, we do not find significant differences between groups related to the client pressure manipulation for both dependent variables. Consequently, we do not find evidence that auditors exhibit less skeptical judgment and action when client pressure is high than when client pressure is low (Hypothesis 1). Rather, in an overall (descriptive) picture, auditors seem to become slightly more skeptical in their judgments and actions when client pressure is high. This might suggest that a reasonableness constraint has been triggered. Tests of mechanisms, based on the estimation of a SEM, further support this conclusion.

Second, we observe a significant direct effect of KAM consideration on the dependent variable skeptical judgment. However, we do not find significant differences between groups for the dependent variable skeptical action. Consequently, as for skeptical judgment, we are able to support Hypothesis 2b: Auditors exhibit significantly less skeptical judgment when KAM consideration is present than when KAM consideration is absent. This suggests that, when considering KAM and due to moral licensing, auditors are more willing to acquiesce to their clients' desired accounting treatments, believing either that KAM communication 
provides a defense for not requiring adjustments, or that KAM communication fulfills the auditors' fiduciary duty to ensure that the investing public has been informed. Hence, our findings suggest that when auditors consider KAM, auditor judgment performance is impaired.

Furthermore, we also investigated the mechanisms through which KAM consideration and client pressure affect our dependent variables whereby we focused on the two factors goal commitment and work effort as potential mediators. In this regard, we can show that (1) consideration of KAM significantly reduces goal commitment, which in turn (2) has a positive (albeit non-significant) effect on participants' assessment of the likelihood that the recoverable amount is reasonable (skeptical judgment), and a significantly negative effect on the likelihood that the auditor requires an adjustment of the estimation of the recoverable amount (skeptical action). Considering the effects (1) and (2) together, KAM consideration might have the potential to lead to more skeptical action through a decrease of goal commitment (in line with Hypothesis 2a). Hence, while the moral licensing effect seems to be dominant, we can provide empirical evidence that KAM consideration also induces a reverse effect on auditors' willingness to acquiesce to the client's preferred accounting through goal commitment. Finally, we find that consideration of KAM also significantly reduces the work effort exerted by participants, which is again indicative of a moral licensing effect, as auditors seem to feel licensed to exert less effort and seem to have less motivation to conduct a thorough audit.

Overall, our findings suggest that KAM reporting requirements might have side effects. By showing that KAM consideration leads to less skeptical judgment, we document that the new KAM reporting requirement - intended to improve the communicative value of the auditor's report for users (IAASB 2012) - comes at the expense of auditor judgment performance. It seems as if auditors who consider KAM feel morally licensed to acquiesce to clients' desired accounting treatments. This finding is of interest for auditors and regulators, as well as users and prepares, by highlighting unintended consequences of KAM reporting. 
Of course, our study is not without limitations. First of all, when we test for the effectiveness of our client pressure manipulation, we can only provide empirical evidence for a successful manipulation of the client pressure component client opposition, but not for client importance. Hence, we have to acknowledge that our client pressure manipulation might be weaker than intended. While the utilized client pressure manipulation has been very successful in prior studies, because of the described findings, it might be fruitful for further research to develop an understanding for the conditions under which this client pressure manipulation works well.

Second, with a total of 70 observations that we use to estimate our SEM in the tests of mechanisms, we do not meet existing rules of thumb for the minimum sample size in structural equation modelling. However, as argued, previous studies have worked with sample sizes comparable to or smaller than our sample size. Furthermore, to mitigate a potential sample size concern, i.e. to validate our findings, in additional analyses, we included observations deleted for the main analyses and reran the SEM, and the results remain largely consistent.

Finally, as in every experiment, we have to acknowledge the risk that our results are driven by the specific design and content of the case. Hence, an interesting avenue for future research might be to look at the effects of KAM consideration on auditor judgment performance in the context of auditing a variety of complex estimates. 


\section{References}

American Institute of Certified Public Accountants (AICPA). 2000. Audit committee communications. Statement on Auditing Standards No. 90. New York: AICPA.

Asbahr, K., and K. Ruhnke. 2017. Real effects of reporting Key Audit Matters on auditors' judgment of accounting estimates. Working paper, Free University of Berlin.

Backof, A., K. Bowlin, and B. Goodson. 2014. The impact of proposed changes to the content of the audit report on jurors' assessments of auditor negligence. Working paper, http://papers.ssrn.com/sol3/papers.cfm?abstract_id=2446057.

Bauer, T. 2015. The Effects of situated client identity and professional identity salience on auditor judgments. The Accounting Review 90 (1): 95-114.

Boiney, L., J. Kennedy, and P. Nye. 1997. Instrumental bias in motivated reasoning: More when more is needed. Organizational Behavior and Human Decision Processes 72 (1): 1-24.

Brasel, K., M. Doxey, J. H. Grenier, and A. Reffett. 2016. Risk disclosure preceding negative outcomes: The effects of reporting critical audit matters on judgments of auditor liability. The Accounting Review (91) 5: 1345-1362.

Brown, T., T. Majors, and M. Peecher. 2015. The influence of evaluator evidence, a judgment rule, and critical audit matters on assessments of auditor legal liability. Working Paper, University of Illinois at Urbana-Champaign.

Cain, D. M., G. Loewenstein, and D. A. Moore. 2011. When sunlight fails to disinfect: Understanding the perverse effects of disclosing conflicts of interest. Journal of Consumer Research 37 (5): 836-857.

Carcello, J. V., and A. L. Nagy. 2004. Audit firm tenure and fraudulent financial reporting. Auditing: A Journal of Practice \& Theory 23 (2): 55-69. 
Christensen, B. E., S. M. Glover, and C. J. Wolfe. 2014. Do critical audit matter paragraphs in the audit report change nonprofessional investors' decision to invest? Auditing: A Journal of Practice \& Theory 33 (4): 71-93.

Cloyd, C. B. 1997. Performance in tax research tasks: the joint effects of knowledge and accountability. The Accounting Review 72 (1): 111-131.

Deloitte. 2016. The Trueblood Case Studies, https://www2.deloitte.com/us/ en/pages/aboutdeloitte/articles/trueblood-case-studies-deloitte-foundation.html.

Geiger, M. A., and K. Raghunandan. 2002. Auditor tenure and audit reporting failures. Auditing: A Journal of Practice \& Theory 21 (1): 67-78.

Ghosh, A., and D. Moon. 2005. Auditor tenure and perceptions of audit quality. The Accounting Review 80 (2): 585-612.

Gimbar, C., B. Hansen, and M. E. Ozlanski. 2016a. The effect of critical audit matter paragraphs and accounting standard precision on auditor liability. The Accouting Review 91 (6): $1629-1646$.

Gimbar, C., B. Hansen, and M. E. Ozlanski. 2016b. Early evidence on the effects of critical audit matters on auditor liability. Current Issues in Auditing 10 (1): A24-A33.

Griffin, J. B. 2014. The effects of uncertainty and disclosure on auditors' fair value materiality decisions. Journal of Accounting Research 52 (5): 1165-1193.

Griffith, E. E., J. S. Hammersley, K. Kadous, and D. Young. 2015. Auditor mindsets and audits of complex estimates. Journal of Accounting Research 53 (1): 49-77.

Hackenbrack, K., and M. W. Nelson. 1996. Auditors' incentives and their application of financial accounting standards. The Accounting Review 71 (1): 43-59. 
Hatfield, R. C., S. B. Jackson, and S. D. Vandervelde. 2011. The effects of prior auditor involvement and client pressure on proposed audit adjustments. Behavioral Research in Accounting 23 (2): 117-130.

Hollenbeck, J. R., C. R. Williams, and H. J. Klein. 1989. An empirical examination of the antecedents of commitment to difficult goals. Journal of Applied Psychology 7 (1): 1823.

Hoyle, R. H., and N. C. Gottfredson. 2016. Sample size considerations in prevention research applications of multilevel modeling and structural equation modeling. Prevention Science 16 (7): 987-996.

International Accounting Standards Board (IASB). 2016. International Accounting Standard 36: Impairment of assets. London: IFRS Foundation.

International Auditing and Assurance Standard Board (IAASB). 2012. Improving the auditor's report: Invitation to comment. New York: International Federation of Accountants.

International Auditing and Assurance Standard Board (IAASB). 2015a. International Standard on Auditing 701. Communicating key audit matters in the independent auditor's report. New York: International Federation of Accountants.

International Auditing and Assurance Standard Board (IAASB). 2015b. Basis for Conclusions: Reporting on audited financial statements - New and revised auditor reporting standards and related conforming amendments. New York: International Federation of Accountants.

International Auditing and Assurance Standard Board (IAASB). 2015c. International Standard on Auditing 260. Communication with those charged with governance. New York: International Federation of Accountants. 
Jamal. K. 2012. Dysfunctional consequences of disclosure. Accounting Horizons 26 (2): 381383.

Jamal, K., E. Marshall, and H-T. Tan. 2016. Does disclosure of conflict of interest increase or decrease bias? Auditing: A Journal of Practice \& Theory 35 (1): 89-99.

Kachelmeier, S. J., J. J. Schmidt, and K. Valentine. 2015. The disclaimer effect of disclosing critical audit matters in the auditor's report, Working paper, The University of Texas at Austin.

Kadous, K., S. J. Kennedy, and M. E. Peecher. 2003. The effect of quality assessment and directional goal commitment on auditor's acceptance of client-preferred accounting methods. The Accounting Review 78 (3): 759-778.

Kahai, S. S., and R. B. Cooper. 2003. Exploring the core concepts of media richness theory: the impact of cue multiplicity and feedback immediacy on decision quality. Journal of Management Information Systems 20 (1): 263-299.

Kerler, W. A., and D. M. Brandon. 2010. The effects of trust, client importance, and goal commitment on auditors' acceptance of client-preferred methods. Advances in Accounting, incorporating Advances in International Accounting 26 (2): 246-258.

Klein, H. J., M. J. Wesson, J. R. Hollenbeck, P. M. Wright, and R. P. DeShon. 2001. The assessment of goal commitment: A measurement model meta-analysis. Organizational Behavior and Human Decision Processes 85 (1): 32-55.

Knechel, W. R., and A. Vanstraelen. 2007. The relationship between auditor tenure and audit quality implied by going concern opinions. Auditing: A Journal of Practice \& Theory 26 (1): 113-131. 
Koch, C., and S. E. Salterio. 2015. Effects of client pressure and audit firm management control systems on auditor judgments, Working Paper, https://papers.ssrn.com/sol3/ papers.cfm?abstract_id $=2572486$.

Koch, C., and S. E. Salterio. 2017. The effects of auditor affinity for client and perceived client pressure on auditor proposed adjustments. The Accounting Review: Forthcoming.

Köhler, A. G., N. V. S. Ratzinger-Sakel, and J. C. Theis. 2016. The effects of key audit matters on the auditor's report's communicative value: Experimental evidence from investment professionals and non-professional investors, Working Paper, https://papers.ssrn.com/ sol3/papers.cfm?abstract_id=2838162.

Kunda, Z. 1990. The case for motivated reasoning. Psychological Bulletin 108 (3): 480-498.

Kunda, Z. 1999. Social cognition: Making sense of people. Cambridge, MA: The MIT Press.

Lennox, C. S., J. J. Schmidt, and A. M. Thompson. 2016. Is the expanded model of audit reporting informative to investors? Evidence from the UK, Working Paper, The University of Texas at Austin.

Libby, R., and M. G. Lipe. 1992. Incentives, effort, and the cognitive processes involved in accounting-related judgments. Journal of Accounting Research 30 (2): 249-273.

Libby, R., and J. Luft. 1993. Determinants of judgment performance in accounting settings. Ability, knowledge, motivation, and environment. Accounting Organizations \& Society 18 (5): 425-450.

Lord, A. T., and F. T. DeZoort. 2001. The impact of commitment and moral reasoning on auditors' responses to social influence pressure. Accounting, Organizations \& Society 26 (3): $215-235$. 
Miller, D. T., and D. A. Effron. 2010. Psychological license: When it is needed and how it functions. Advances in Experimental Social Psychology 43: 115-155.

Monin, B., and D. T. Miller. 2001. Moral credentials and the expression of prejudice. Journal of Personality and Social Psychology 81 (1): 33-43.

Nelson, M. W. 2009. A model and literature review of professional skepticism in auditing. Auditing: A Journal of Practice \& Theory 28 (2): 1-34.

Ng, T., and H-T. Tan. 2003. Effects of authoritative guidance availability and audit committee effectiveness on auditors' judgments in an auditor-client negotiation context. The Accounting Review 78 (3): 801-818.

Nunnally, J. C. 1967. Psychometric theory. New York, NY: McGraw Hill.

Public Company Accounting Oversight Board (PCAOB). 2011. Concept Release on auditor independence and audit firm rotation. PCAOB Concept Release No. 2011-006 (August). Washington: PCAOB.

Public Company Accounting Oversight Board (PCAOB). 2016.Proposed Auditing Standard: The auditor's report on an audit of financial statements when the auditor expresses an unqualified opinion and related amendments to PCAOB Standards. PCAOB Release No. 2016-003 (May). Washington: PCAOB.

Salterio, S., and L. Koonce. 1997. The persuasiveness of audit evidence: The case of accounting policy decisions. Accounting, Organizations \& Society 22 (6): 573-587.

Shaub, M. K., and J. E. Lawrence. 2002. A taxonomy of auditors' professional skepticism. Research on Accounting Ethics 8: 167-194.

So, J. C. F., and N. Bolloju. 2005. Explaining the intentions to share and reuse knowledge in the context of IT service operations. Journal of Knowledge Management 9 (6): 30-41. 
Teoh, S. H. 1992. Auditor independence, dismissal threats, and the market reaction to auditor switches. Journal of Accounting Research 30 (1): 1-25.

Trompeter, G. 1994. The effect of partner compensation schemes and generally accepted accounting principles on audit partner judgment. Auditing: A Journal of Practice \& Theory 13 (2): 56-68.

Van Raaij, E. M., and J. J. L. Schepers. 2006. The acceptance and use of a virtual learning environment in China. Computers \& Education 50 (3): 838-852.

Venkatesh, V., and F. D. Davis. 2000. A theoretical extension of the technology acceptance model: four longitudinal field studies. Management Science 46 (2): 186-204.

Westland, J. C. 2010. Lower bounds on sample size in structural equation modeling. Electronic commerce research and applications 9 (6): 476-487.

Wilcox, K., B. Vallen, L. Block, and G. Fitzsimons. 2009. Vicarious goal fulfillment: When the mere presence of a healthy option leads to an ironically indulgent decision. Journal of Consumer Research 36 (3): 380-393.

Windsor, C. and M. Kavanagh. 2012. Auditor independence and client economic power: Qualitative evidence and propositions involving auditors' emotions and moral reasoning, Working Paper, Available at: http://epublications.bond.edu.au/cgi/ viewcontent.cgi?article $=1664 \&$ context $=$ business_pubs.

Yoo, Y., and M. Alavi. 2001. Media and group cohesion: relative influences on social presence, task participation, and group consensus. MIS Quarterly 25 (3): 371-390. 


\section{Tables}

\section{TABLE 1}

Goal commitment measurement

Goal Commitment Question and Goal

There are several plausible goals that you could have had while considering Alpha's estimation of the recoverable amount. Please indicate how important the following goal was to you by rating the extent to which you agree or disagree with each statement for the following goal.

Goal: Build a justifiable case for characterizing Alpha's estimation of the recoverable amount to be acceptable in the circumstances.

\begin{tabular}{llc}
\hline Variable in SEM & Item to Provide Agreement Rating & Response Scale \\
\hline $\mathrm{X}_{1}$ & I thought this was a good goal to shoot for. & $\begin{array}{c}\text { Disagree } \\
\text { completely }\end{array}$ \\
$\mathrm{X}_{2}$ & I was strongly committed to pursuing this goal. & $=1$ \\
$\mathrm{X}_{3}$ & It was hard to take this goal seriously. & Agree \\
$\mathrm{X}_{4}$ & Quite frankly, I didn't care if I achieved this goal or not. & completely \\
$\mathrm{X}_{5}$ & It wouldn't have taken much to make me abandon this goal. & $=5$ \\
\hline
\end{tabular}


TABLE 2

ANOVA results for dependent variable skeptical judgment

\begin{tabular}{|c|c|c|c|c|c|}
\hline Source & Partial SS & $\mathrm{df}$ & $\mathrm{MS}$ & $\mathrm{F}$ & Prob $>F$ \\
\hline Model & 18.6104 & 3 & 6.2035 & 1.22 & 0.3075 \\
\hline Client Pressure & 0.0827 & 1 & 0.0827 & 0.02 & 0.8987 \\
\hline KAM Consideration & 15.2189 & 1 & 15.2189 & 3.00 & 0.0875 \\
\hline Interaction Term & 3.1525 & 1 & 3.1525 & 0.62 & 0.4329 \\
\hline Residual & 349.6089 & 69 & 5.0668 & & \\
\hline Total & 368.2192 & 72 & 5.1142 & & \\
\hline \multicolumn{4}{|c|}{ Number of observations $=73$} & \multicolumn{2}{|c|}{$\begin{aligned} \text { R-squared } & =0.0505 \\
\text { Adj. } R \text {-squared } & =0.0093\end{aligned}$} \\
\hline
\end{tabular}




\section{TABLE 3}

Summary of results

\begin{tabular}{clrrrrr}
\hline Construct $^{\mathrm{a}}$ & Predictor & Path Coefficient & $\mathrm{z}$ & $\mathrm{P}>$ & $\mathrm{z}$ & [95 \% Confidence Interval] \\
\hline Likelihood that & Client Pressure & 0.0353 & 0.07 & 0.946 & -0.9811 & 1.0518 \\
recoverable amount & KAM Consideration & 1.1679 & 2.10 & 0.036 & 0.0779 & 2.2579 \\
is reasonable & Goal Commitment & 0.8735 & 1.03 & 0.305 & -0.7944 & 2.5413 \\
(skeptical judgment) & Work Effort & -0.0704 & -0.61 & 0.541 & -0.2965 & 0.1556 \\
& & & & & & \\
Liquelihood to & Client Pressure & 0.9190 & 2.32 & 0.020 & 0.1427 & 1.6954 \\
require adjustment & KAM Consideration & 0.2508 & 0.57 & 0.567 & -0.6089 & 1.1105 \\
(skeptical action) & Skeptical Judgment & -0.6233 & -6.79 & 0.000 & -0.8033 & -0.4433 \\
& Goal Commitment & -1.3575 & -1.77 & 0.077 & -2.8626 & 0.1475 \\
& Work Effort & 0.2319 & 2.63 & 0.008 & 0.0592 & 0.4046 \\
& & & & & & \\
Goal Commitment & Client Pressure & 0.0802 & 0.78 & 0.433 & -0.1204 & 0.2808 \\
& KAM Consideration & -0.2047 & -1.71 & 0.087 & -0.4391 & 0.0297 \\
& & & & & & 1.4023 \\
Work Effort & Client Pressure & 0.3557 & 0.67 & 0.505 & -0.6908 & -0.2599 \\
\hline
\end{tabular}

Likelyhood ratio test of model vs. saturated: $\operatorname{chi}^{2}(24)=26.36$, Prob $>\operatorname{chi}^{2}=0.3349$

Overall equation-level goodness of fit: $\mathrm{R}^{2}=0.2705$

${ }^{\mathrm{a}}$ Measurement level has been omitted for clarity. 
Figures

Figure 1 Structural Equation Model - Outline.

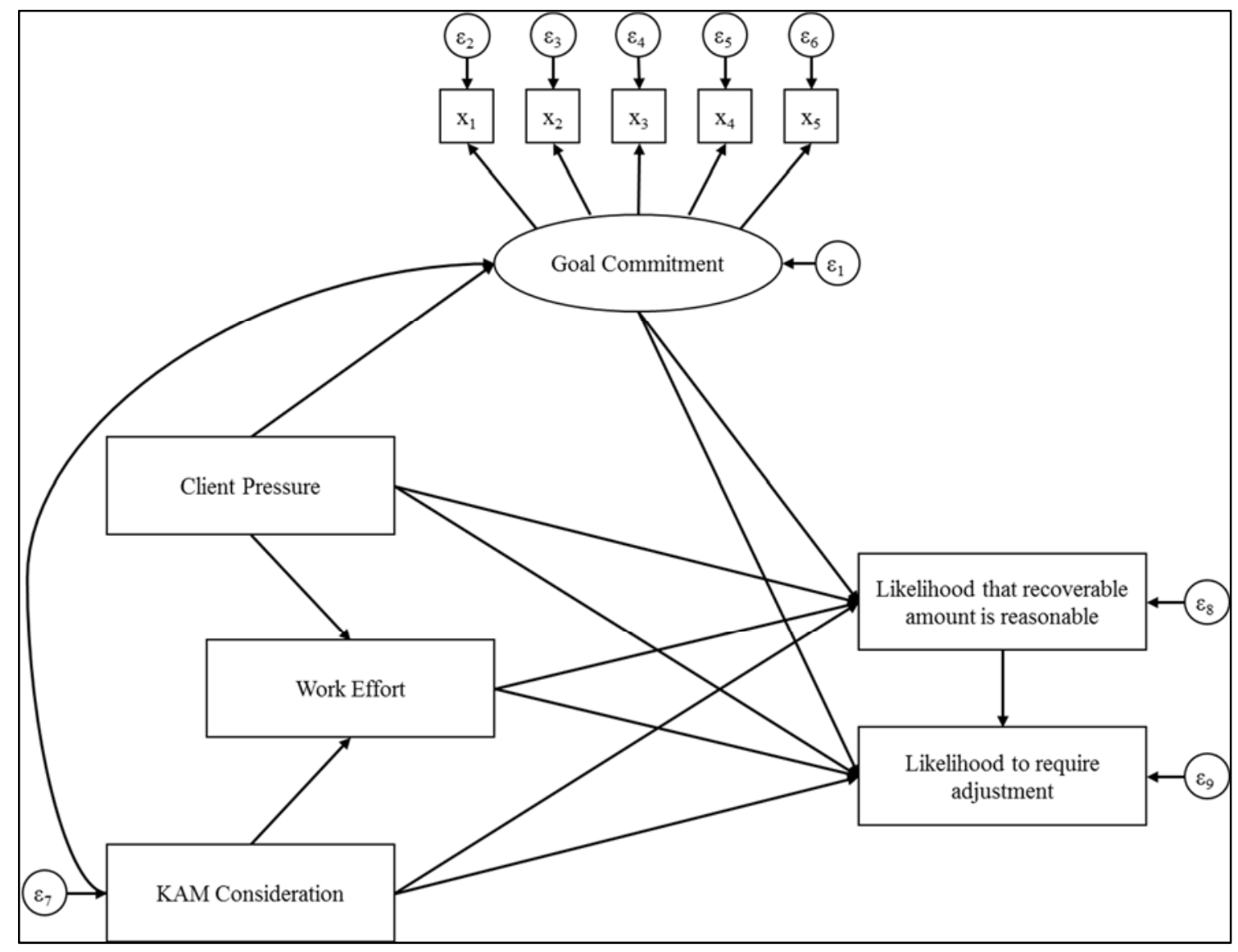


Figure 2 Descriptive results for dependent variables.

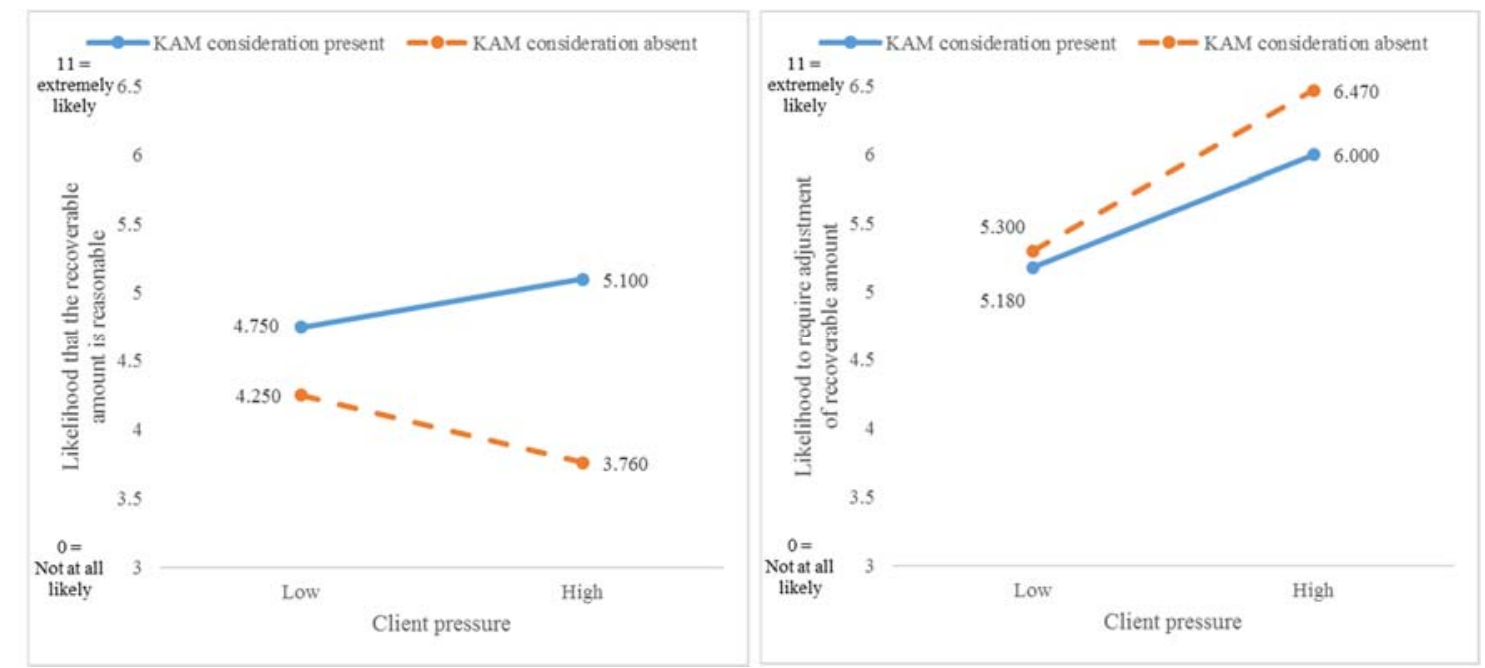


Figure 3

Structural Equation Model - Results.

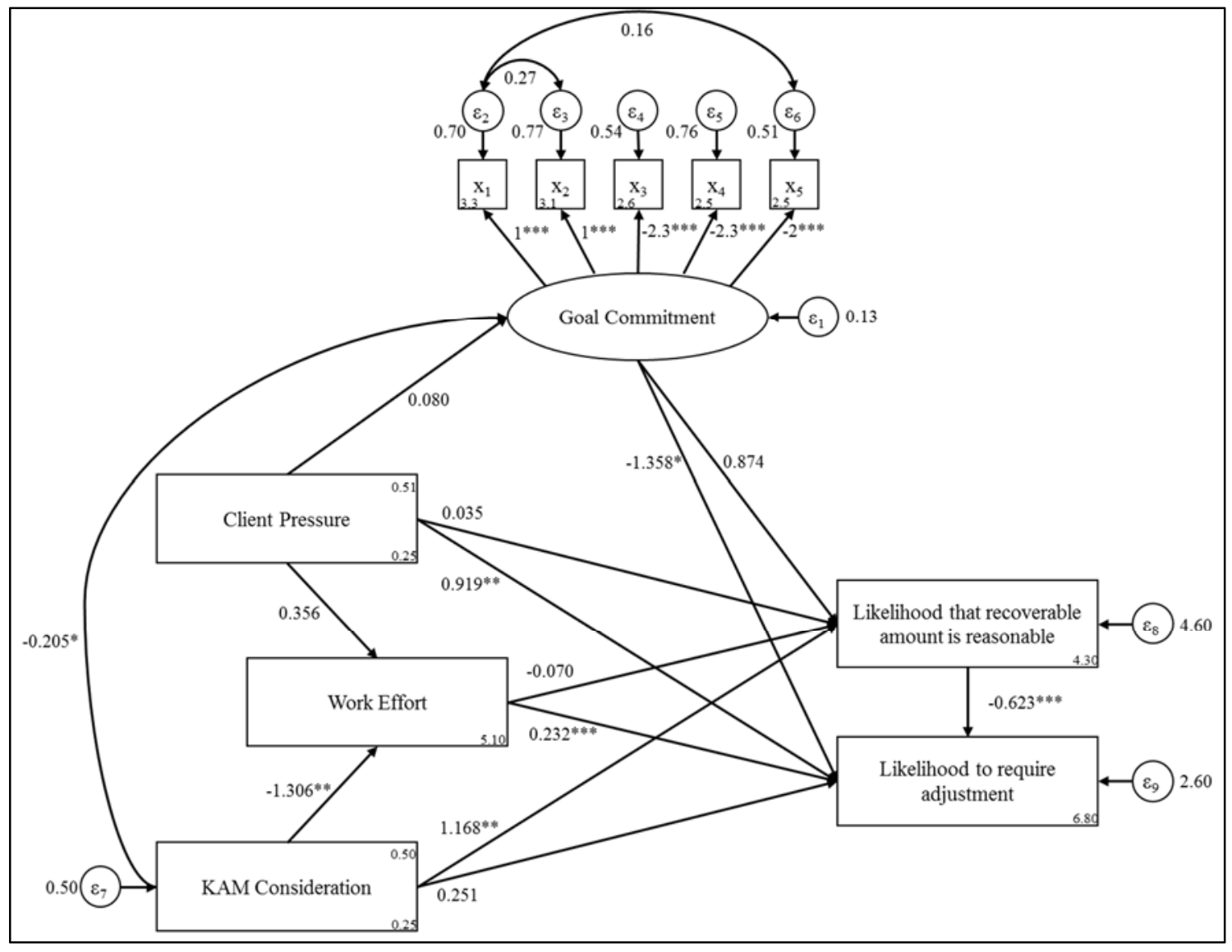

